Article

\title{
Redeeming Emotion-Focused Therapy: A Christian Analysis of Its Worldview, Epistemology, and Emphasis
}

\section{Todd Hardin}

The Southern Baptist Theological Seminary, 2825 Lexington Road, Louisville, KY 40280, USA; E-Mail: revhardin@gmail.com; Tel.: +1-865-399-8165

Received: 7 December 2013; in revised form: 28 February 2014 / Accepted: 3 March 2014 / Published: 10 March 2014

\begin{abstract}
While emotion-focused therapy (EFT) offers clinically useful information to Christian practitioners, its underlying worldview, epistemology, and emphasis present challenges for Christian therapists. This article advocates that Christian practitioners can redeem EFT for Christ by evaluating and translating these presuppositions in light of Christian alternatives. In offering these alternatives, the article encourages the creation of a distinctively Christian emotion-focused therapy (CEFT).
\end{abstract}

Keywords: Christian psychology; emotion-focused therapy; counseling methodology

\section{Introduction}

Emotion-focused therapy (EFT) is an empirically validated treatment approach that has proven useful in treating maladies such as depression [1], anxiety [1], and eating disorders [1]. Emanating from the humanistic school of psychology [2], EFT posits three foundational philosophical tenets. First, EFT views people, their problems, and the solution to those problems through the lens of “neo-humanism” ([1], pp. 20-23). Second, EFT contends that change occurs through a process called dialectical constructivism [1]. Third, EFT emphasizes the role of emotion, particularly the conceptualization of something called an "emotion scheme", in the treatment of people ([1], p. 25).

Since EFT has demonstrated its clinical usefulness, Christian clinicians could benefit from evaluating this therapeutic approach for its appropriateness in their own clinical work. However, practitioners must not haphazardly incorporate elements of any theory without carefully understanding how the theory's underlying presuppositions relate to a Christian worldview. To rightly practice a Christian informed EFT, one must realize that it is more complicated than simply picking interventions or 
mixing and matching concepts to fit one's preferences. Johnson brings out this complexity when he correctly observes, "We are not dealing here with two different disciplines-psychology and theology - but with two different communities, each which possesses a distinct psychological literature” ([3], p. 2975). These different "literatures" are composed of different languages, or at the very least, different dialects [3]. Unfortunately, these community, literary, and linguistic differences are lost on some Christian therapists who implement secular theories into their practices without critically evaluating the approach’s basic assumptions. This “weak conceptual integration” ([3], p. 1144) typically results in a Christianized form of the secular approach that remains virtually indistinguishable from its secular counterpart. This problem stems from translators unintentionally neglecting the commitments of their native community (Christianity) in an effort to immerse themselves into the culture of the foreign community (secular psychology). Moreover, since a community's language inevitably reveals its values, "getting lost in translation” inevitably affects counseling goals. Therefore, to practice counseling Christianly, Christian therapists must continually remember their community's understanding of the practitioner's role as that of an ambassador of the King (2 Cor 5:20) and how the King calls clinicians, regardless of their orientation, to incarnate His “character," "message," and “methods” ([4], p. 107). The counselor desiring to use EFT principles "Christianly” must ask questions such as, "How can I faithfully represent the character that motivates [Jesus'] redemptive work?" "What does my Lord want to communicate to this person in this situation?" and "What responses are consistent with the goals and resources of the gospel” ([4], p. 107)? To think Christianly about EFT means that the therapist must hold to a "religious monism" that humbly asserts that the Creator God does not recognize a distinction between the secular and sacred [5]. In shattering this false dichotomy, Christian therapists should remember Kuyper's contention that, "There is not an inch in the whole area of human existence [including EFT] of which Christ, the sovereign of all does not cry, 'It is mine!'” ([6], p. 117) and as such, Christian therapists can glorify God through redeeming EFT for Christ.

Before proceeding, I need to explain why I am using the term "redeeming” in this article. The evidence shows that, from a Christian perspective, EFT is a good gift of God's common grace (James 1:17) that can be enjoyed by Christian therapists (1 Tim 6:17). Enjoyment, however, does not mean that Christian practitioners are free to practice it in isolation from God's sovereign reign over all the creation. To view EFT as an amoral entity discounts the pervasiveness of the Fall (Rom 8:18-23) and its subsequent need for redemption. A robust Christian psychology sees EFT as an aspect of the tainted creation that needs rescuing for the glory of God. This redemption occurs as faithful Christian practitioners carefully think about the propositions undergirding EFT and take them "captive to the obedience of Christ” (2 Cor 10:5). Before elucidating how to redeem EFT for Christ, it is helpful to review the efforts already exerted to accomplishing this task.

Surprisingly, despite its empirical support and growing popularity in counseling, there has been little written from Christian therapists evaluating EFT's utility for its use from a Christian perspective [7]. Some work has been conducted related to how specific models of integration may be specifically applied to Emotion-Focused Couples Therapy [8]. Also, some preliminary theorizing has been conducted in applying Johnson's “translating” EFT into the dialect of Christian psychology, but there is more to be ascertained about how one might think Christianly about EFT [9]. Besides these Christian theorists, some thought has been given to the clinical application of a Christian form of EFT [10]. McFee and Monroe contend that, “An EFT informed Christian psychology would employ a strong 
experiential emphasis allowing for a more expansive knowledge and incorporation of historic Christian practices” ([9], p. 326). One cannot incorporate Christian practices into EFT without first contemplating EFT's worldview, epistemology [11], and emphasis. Such consideration is necessary because worldviews frame epistemologies and epistemologies influence emphases. For example, a therapy that holds to a modernistic worldview will exclude metaphysical realities from its knowledge base thereby excluding spiritual practices such as prayer from its emphasis. This article extends McFee and Monroe's work by advocating that Christian therapists may redeem EFT for Christ by evaluating and translating the non-Christian presuppositions underlying its worldview, epistemology, and emphasis with Christian presuppositions and utilizing it along with Christian content. Moreover, this essay provides an overview of EFT, analyzes its major presuppositions analogous to these three areas, and articulates some helpful ways Christian therapists can glorify God by constructing and practicing an explicitly Christian emotion-focused therapy (CEFT).

\section{A Brief Overview of EFT}

\subsection{Historical Background}

EFT traces its origins to Carl Rogers’ person-centered therapy [1]. Besides Roger’s influence, EFT incorporates aspects of "gestalt therapy, experiential therapy, and existential therapy with modern emotion, cognitive, attachment, psychodynamic, and narrative theory” ([1], pp. 263-68). This synthesis results in an empathic therapeutic approach that addresses intrapsychic and interpersonal conflict by accessing an individual's affective system in the hopes of helping the person construct new meaning by adaptively processing these conflicts in a safe environment. Like any approach, EFT holds to some major tenets that provide a foundation for its theory.

\subsection{Major Tenets}

As adverted to earlier, EFT holds to three major philosophical tenets. This section elaborates on them and later will revisit them via a critique. As already attributed, EFT flows from a life philosophy known as neo-humanism. In elucidating neo-humanism, Elliott and colleagues contend that EFT holds "that experience is central, that people are greater than the sum of their parts, that people are capable of self-determination, that a growth tendency exists in all clients, and that therapists need to be authentic and present with their clients” ([2], p. 4). Also, neo-humanism advances past its humanistic predecessor by taking advantage of modern emotion theory and affective neuroscience [1].

As mentioned earlier, EFT relies on a post-modern understanding of knowledge called dialectical constructivism. Dialectical constructivism maintains "that in coming to know a thing, both the state of one's knowledge and the thing itself are changed” ([2], p. 36). Simply put, this means that dialectic constructivism asserts that as humans participate in dialogue with distinct aspects of themselves, others, and their environments, they create new meanings and understandings. EFT holds that permeable cognitive/affective structures called emotion schemes organize these experiences.

These emotion schemes are analogous to cognitive schemas except that emotion schemes include emotion as a part of their structure, and they are continually "in process" and transforming that structure. These theorists claim that schemas imply a fixed and static structure, while emotion schemes 
emphasize the permutability of the human psyche that, according to humanistic theory, is always a work-in-process, with an inevitable tendency to growth [2]. In differentiating emotion schemes from cognitive schemas, Elliott and colleagues believe "An emotion scheme is a process rather than a thing. Emotion scheme processes can include linguistic components but often consist largely or entirely of preverbal elements...they are also active and, ultimately, action oriented” ([2], p. 25). EFT also emphasizes that these emotion schemes "are not directly available to awareness" ([2], p. 25), and are composed of five distinct elements.

Elliott and colleagues place emotion scheme elements into the following categories. First, "Perceptual-situational elements represent the person's past or current environments and include immediate awareness of the current situation and episodic memories” ([2], p. 26). Second, "Bodily-expressive elements represent emotion scheme processes through the body" ([2], p. 27). Third, "Symbolic-conceptual elements are verbal or visual representations of the emotion scheme processes through reflective self-awareness of perceptual-situational and bodily-expressive schematic elements” ([2], p. 27). Fourth, "Motivational-behavioral elements are activated by the emotion scheme processes and represent it in the form of associated desires, needs, wishes, intentions, ... or action tendencies” ([2], p. 27). Finally, "The emotion scheme nuclear process organizes all of the different components around a particular emotion... and is often recognized after self-reflection on the other four elements” ([2], p. 27). EFT calls for its practitioners to partner with the client in helping the client, activate, explore, express, and reflect on these emotion schemes [2]. EFT's primary treatment modality and its clinical techniques reveal the influence of these tenets.

\subsection{Modality and Techniques}

While EFT makes use of the narrative modality [12], its major focus is on the emotion modality and "involves the activation and regulation of the emotion regions of the brain.” ([3], p. 797) EFT helps clients bring to awareness previously inaccessible experiences through the indirect activation of emotion schemes. By using emotional experience as the pathway into these structures, EFT helps clients create new experiences through an internal dialectical process whereby the client creates healthier mood states by synthesizing conflicted aspects of the self.

To resolve conflicts in the self, EFT therapists employ several techniques. First, they use empathy and exploration in helping clients become aware of these often unconsciously maintained conflicts to deconstruct “clients' worldviews, constructions, and assumptions about self and others” ([2], p. 113).

Second, EFT uses a six-step structured approach in helping clients resolve disowned emotional experiences. First, the therapist looks for specific markers that point to deeper client problems. Next, the therapist asks the client to delineate the dilemma. Third, the therapist helps the client deepen his or her experience of the dilemma by helping the client access the underlying primary emotions associated with the problem. Fourth, the therapist helps the client clarify his or her relationship to the problem. Fifth, the therapist assists the client in appreciating and owning his or her primary emotion related to the problem. Finally, the therapist helps the client experience relief and empowerment by relating to the problem in an emotionally adaptive way [2].

Third, when individuals struggle with conflict between opposing aspects of the self, EFT advocates using the Gestalt technique known as two-chair work [2]. In this technique, the EFT therapist has the 
client first delineate the fracture between the opposing aspects of the self and then express the underlying feelings associated with each side of the split. The therapist then helps the client express new needs and wants associated with these newly discovered feelings and leads the client to accept these feelings with compassion, thereby reconciling the conflicted self [2].

Fourth, when individuals struggle with conflict associated with "unfinished interpersonal issues", EFT recommends another Gestalt intervention known as the empty chair technique ([2], p. 243). In this technique, the client verbally expresses his or her concern to the empty chair as if his or her "antagonist” was present. Then, the client switches seats (and roles) by responding from the “antagonist's" perspective. During the discussion, the client expresses his or her underlying emotional responses to the other person, perhaps asserting any unmet needs. Then, the client shifts roles again and responds as the other person in a more positive way and the procedure concludes with the client affirming his or her "other" self and "letting go of unresolved feelings by understanding, forgiving, or holding the other person accountable," This modality and its accompanying techniques help individuals grow by resolving inner and interpersonal conflicts through the adaptive activation, exploration, and reflection on primary emotions associated with these conflicts. We turn next to contemplate EFT's understanding of health, sickness, and telos.

\subsection{Health, Sickness, and Telos}

EFT views healthy individuals as self-actualizing beings with an innate tendency to growth. With such growth as a mark of maturity, theorists consider psychological health "...as the ability to creatively adjust to situations and to be able to produce novel responses, experiences, and narratives” ([1], p. 303). Conversely, EFT views pathology as a stagnation of growth characterized by an avoidance of primary emotional experience, the employment of maladaptive emotions in obscuring primary emotions, as well as a rigidity in cognitive processes that stem from unresolved intra- or inter-personal conflict [1]. Therefore, "the goal of treatment is to transform maladaptive emotion responses and gain access to adaptive emotional responses to guide the process of becoming” ([1], pp. 303-08).

\section{A Christian Appraisal of EFT's Major Tenets}

\subsection{Worldview}

All counseling theories represent a specific worldview. Consequently, the successful application of any theory depends on the therapist's acceptance of the theory's particular view of reality [2]. With this being the case, one might say that therapy has more in common with philosophy than medicine, since counseling implicitly attempts to help people change their problematic philosophical commitments in the hopes of promulgating psychological health, whereas medicine seeks to change body chemistry in the hopes of promoting bodily health. Since worldviews consist of some of these deeply held beliefs, one often cannot effectively counsel others without acknowledging, interacting, and occasionally, adjusting them. Before exploring worldview assumptions, maybe a definition of worldview will prove helpful. Sire defines worldview as:

... a commitment, a fundamental orientation of the heart, that can be expressed as a story or

in a set of presuppositions (assumptions which may be true, partially true or entirely false) 
which we hold (consciously or subconsciously, consistently or inconsistently) about the basic constitution of reality, and that provides the foundation on which we live and move and have our being ([13], p. 1179).

As a descendent from the person-centered therapy school, and despite its incorporation of current emotion theory and affective neuroscience, EFT's major worldview assumptions are ultimately derived from humanism. These assumptions can be summarized in four broad themes that are evident in current EFT theory. First, humanistic therapy advocates hold to a phenomenological approach, which means that they are "grounded in the belief in the unique human capacity for reflective consciousness, and in the belief that [these capacities] can lead to self-determination and freedom” ([14], p. 1179). Second, humanistic therapy advocates also believe in "the operation of some form of actualizing or growth tendency” ([14], p. 198). Human beings always have the potential for growth and never remain static. Third, humanistic therapy advocates believe in the "human capacity for self-determination ([14], p. 198).” Finally, they maintain a person-centered view of therapy [14].

EFT's humanistic worldview serves as a mixed blessing for those desiring to practice CEFT. Its person-centeredness values the dignity and special nature of the human being, echoing God's view of the person as an image bearer (Gen 1:27). In addition, in one way, the humanist understanding of self-determination reflects an affirmation of personal agency. The Bible likewise encourages individuals to take responsibility for their actions (Deut 24:16), and viewed from this perspective, the humanistic focus on "choice" can also be a good thing. However, the humanistic emphasis on reflective consciousness as a pure path to self-determining freedom discounts the noetic effect of sin (Rom 3:10-12) and obscures the dependency of humans on God's goodness (Jn 15:5). Humanism tends to exalt the creature above the Creator (Rom 1:22-23) and because of the darkness of human hearts (Jer 17:9), lives governed in this way, from a Christian perspective, tend to the chaotic [15]. Carried to the extreme, a humanistic worldview can lead to a culture where "everyone does what is right in his own eyes" (Judges 21:25).

Furthermore, CEFT cannot ignore the ethical and spiritual components of life and must incorporate them into its overall telos. Those who practice CEFT, like their secular counterparts, can honor clients' personhood and encourage their personal agency while working to reorient them to God through the cross of Christ as they activate, explore, express, and reflect on difficult emotional experiences. Moreover, Christian practitioners, unlike unbelieving EFT clinicians, promote Christoformity instead of self-actualization (Rom 8:29ff; Eph 5:1). CEFT heeds Schaeffer's warning that humanism "is the placing of Man at the center of all things and making him the measure of all things” ([15], p. 110). Instead, CEFT earnestly seeks to "labor until Christ is formed" (Gal 4:19) in the hearts of its clientele. The question becomes, "How can those who practice CEFT faithfully represent the character that motivates Christ's redemptive work” ([4], p. 107)?

Christian practitioners promote client Christoformity by becoming circumspect of their own worldview influences, heart orientations, and story lines. Effective Christian clinicians manifest a progressively deepening humility wrought from consistent communion with God through self-examination, biblical meditation, and prayer. The Spirit uses such means of grace to increase awareness of one's existence Coram Deo (before the face of God), and impart understanding analogous to one's place in God's redemptive narrative. This process deepens Christian counselors' 
experiential union with Christ, which leads to increasingly wise counsel (James 3:17) that is self-aware, committed to the love of God and neighbor, and interpreted through the lens of the Christian ground motive (creation, fall, redemption, and consummation) [16]. In essence, the Holy Spirit uses the heart of the Christian practitioner as a conduit of grace promulgating worldview change in clients (1 Pet 4:10).

\subsection{Epistemology (Way of Knowing)}

As already discussed, EFT's worldview presuppositions adhere to an epistemology known as dialectic constructivism. Christianity is not a stranger to dialectic processes. For example, the apostle Paul discussed the multiplicity of the self in his letter to the Ephesians. Paul characterized this multiplicity as a battle between his "old self" (i.e., the flesh) and his "new self" (i.e., the spirit) (Eph 4:22-24). Whereas EFT focuses on discovering silenced parts of the subordinate self while constructing one's own meaning, Christianity emphasizes the stark contrasts between opposing parts of the self while receiving meaning from a transcendent Redeemer (Rom 7:24-25).

CEFT also finds a Christian dialectic discussed in the writings of Soren Kierkegaard. Like EFT, Kierkegaard cared about the internal experiences of people. However, Kierkegaard developed a distinctively Christian understanding of human experience through what he called an "inverse dialectic" ([17], p. 7). Inverse dialectic occurs when "the positive is known and expressed through the negative, what appears to be negative may be indirectly positive (and vice versa), and the positive and the negative, Christianly understood, are always the inverse of the natural, human, worldly, and pagan understandings of these terms” ([17], pp. 7-8). Jesus modeled this thinking with statements like, "He who has found his life will lose it, and he who has lost his life for My sake will find it” (Matt 10:39).

Albeit an extended discussion of Kierkegaard's dialectic and epistemology [18] lies outside the scope of this article, Walsh argues that Kierkegaard identified four major inverse dialectics. First, Kierkegaard differentiated "the consciousness of sin" and "faith and forgiveness"; second, "the possibility of offense" from "faith"; third, "dying to the world, and self-denial” and "new life, love, and hope in the Spirit"; and finally, "suffering" and "joy and consolation" ([17], p. 14). For Kierkegaard, living Christianly involved first examining the negative side of the dialectic thoroughly to procure a lucid understanding of it. Then, he advocated connecting the negative aspect of the dialectic to its antithesis. By doing this, Kierkegaard argued, the Christian could experience the positive side of the dialectic in the fullest sense. In other words, Kierkegaard thought that only through acknowledging, exploring, and embracing the negative aspects of existence could the Christian fully experience the positive aspects of the Christian life such as "faith, forgiveness, new life, hope, joy and consolation” ([17], pp. 14-15). Simply stated, in these inverse dialectics the shadows of human existence reveal the sunlight. By calling attention to these darker aspects of human life, God indirectly communicates [19] the light of his love, grace, and acceptance more deeply into the hearts of believers, so that they experience God's presence and meaning in the midst of their trials. While EFT rightly seeks to resolve conflicted aspects of the self by accessing emotion schemes, a robust CEFT will go further by also addressing the conflicting relational experience of the person Coram Deo. As Christian practitioners repeatedly help clients explore such inverse dialectics, they will become increasingly proficient in answering, "What does the Lord want to communicate to this person in this situation” ([4], p. 107)? 
In contrast to a Kierkegaardian inverse dialectic, EFT's dialectical constructivism, focuses almost exclusively on the temporal experience of the client to the exclusion of the eternal. While dialectical constructivism reduces intrapsychic hostility, it does not resolve the hostility between God and the client, a resolution requiring redemption through Christ. Besides working with the different "parts" of clients as is done in dialectical constructivism, CEFT utilizes an inverse dialectic in the exploration of the client's soul. Examples include, searching for signs of joy and consolation in the midst of suffering, or seeking faith and forgiveness when conscious of sin. By doing so, God uses CEFT in drawing clients into higher orders of meaning while inserting Himself into their experiences.

\subsection{Emphasis}

As earlier adverted to, EFT emphasizes the role of emotion in therapeutic change. Instead of focusing on cognitive schemas, EFT promotes counselee growth by modifying emotion schemes.

The Christian therapist can ascertain much from EFT's concept of an emotion scheme. Throughout the history of pastoral care, there has been diversity in conceptualizations of the soul. The Puritan John Owen, for example, divided the heart into the mind, will, and affections [20] whereas Jonathan Edwards separated the affections and the understanding [21]. Therefore, in the absence of a unified understanding of the soul, EFT may offer CEFT additional ways of understanding parsings of the heart. For example, EFT's "perceptual-situational” element seems analogous to what Calvin [22], Sibbes [23] and Charnock [24] called the imagination. Biblically, the perceptual-situational element finds a corollary in the Hebrew term yeser (Is 26:3), which is the mind's ability to think in images and pictures [25]. In addition, EFT's understanding of the "bodily-expressive" element of an emotion scheme seems to resonate with David's contention that there are bodily responses to troubles of the soul (Pss 31:10; 32:1-5). Moreover, as one reflects on the perceptual-situational and bodily-expressive elements of the emotion scheme, and seeks to put them into words, one gains the ability to verbalize and assign meaning to one's experience. This articulation of meaning can be facilitated as individuals recognize how their experience fits into the story line of the Christian metanarrative. Scripture shows this type of activity as the beleaguered Psalmist calls out to God in his time of distress, only to find himself comforted as he slowly makes sense of his place in the "big picture" of God's Redemption Story (cf. Ps 77). Next, as clients activate, explore, express, and reflect on particular emotion schemes, they become more cognizant of the motives and ruling desires that have alienated them from God. CEFT helps disoriented clients reorient to God through the cross of Christ by repenting of sin (1 John 1:9), calling out in faith during suffering (Pss 42:5; 56:3), and boasting in personal weaknesses (2 Cor 12:9) [26]. By naming the emotion related to the emotion scheme, Christian clients expose it to the light of the gospel, create a new Christianized episodic memory of their story, and change the direction of their narrative. Therefore, by thinking Christianly, those practicing CEFT can safely utilize the emotion scheme concept when working with clients. EFT's assertion that there is a primary emotion that must be accessed coheres with the writings of Scripture and the Christian tradition. The prophet Jeremiah contended that the heart was "sick" and implied its complex and mysterious nature by asking "Who can understand it" (Jer 17:9)? In commenting on the pervasiveness of the Fall, Schaeffer acknowledged the existence of the unconscious and argued that it was a battleground where humanity experienced intra-personal alienation and stored interpersonal conflict. Schaeffer commented that: 
It is no wonder, then that by the Fall man is not only divided from other men (as Cain kills Abel, for example), but is also divided from nature and from himself...It is not only that man is divided from his body; he is divided from himself in the thought-world of which we spoke. Man in the present life is divided in his personality... (italics original) ([27], pp. 113-14).

Van Til agreed with Schaeffer's understanding of pre-fall humanity and contended that the unconscious, like the rest of God's creation was originally good. Van Til observed that:

As Christians we believe that man was originally created with the love of God in his heart. That is, we believe that man was priest as well as prophet. More than that, we also believe that man was part conscious and in part unconscious in his activity. We hold that man was created as a character. That is, we maintain that in his unconscious as well as in his conscious activity man was directed toward God ([28], p. 71).

In viewing the unconscious in this way, both Schaeffer and Van Til were acknowledging its existence and activity while echoing the plain teachings of scripture. These teachings acknowledge the existence of an active unconscious and encourage individuals to bring disowned experiences from the dark and into the light. For example, David implied the existence of an active unconscious when he implored God to make an exhaustive search of the places in his heart that he was unknowingly sinning against Him (Ps 139:23). These ideas about making the unconscious conscious also seem to cohere with Scripture's admonition for self-examination (2 Cor 13:5) and the acknowledgment of one's internal soul states (Pss 42:5, 11; 43:5) during times of emotional distress. Since Scripture and the Christian tradition both acknowledge the existence and activity of the unconscious, one must next ascertain how best to access the unconscious in a redemptive way.

Christianity agrees with EFT in its contention that the unconscious, to use Van Til's term, or better understood from EFT's perspective, the emotion scheme, is implicit and best accessed indirectly [29]. In discussing the problem of helping falsely converted parishioners, Kierkegaard claimed that they were under a "prodigious illusion" and the only way to effectively help them was to "approach from behind the person who is under [such] an illusion ([30], p. 332)" One also finds this type of indirect approach in the scriptural narrative of Nathan's confrontation of David (2 Sam 12:1-15) and Jesus' use of paradox in his teaching (Luke 18:18-23).

While maintaining the centrality of affective experience, and recognizing the implicit nature of emotion schemes and the need for an indirect approach in accessing these structures, the question remains, "How can CEFT be practiced in a theologically orthodox way?" Said differently, how can those who practice CEFT use a process-experiential approach in a way that evokes client healing while being guided by the goals and resources of the gospel [4]?

The short answer to this question is that there is still more work needed. Although still in its infancy, to this point, there have been some initial forays into ways that clinicians can utilize experiential techniques helping individuals activate, explore, express, and reflect on primary emotions through the lens of a Christian framework [10]. Kim-Van Daalen and Johnson (in press) have focused on providing clients with a kerygmatic (see 1 Cor 15:1-5) experience related to disowned emotional experiences. They recommend that those practicing CEFT create safe spaces for clients to acknowledge and surrender their sin, weaknesses, and faults to Christ by helping them symbolically 
nail them to the cross. This approach also promotes an atmosphere of love and acceptance in that the procedure also calls for the client to bask in the warmth and grace of the resurrected Jesus as He symbolically embraces the client and "remembers their sin no more” (Jer 31:34) [26]. Although research needs to be conducted on this model, it appears that these writers have captured the essence of a Christ-centered approach to CEFT.

\section{Conclusions}

This article has argued that there are three foundational requirements for a Christian Emotion-Focused Therapy theory. First, CEFT should incarnate the character of the King by encouraging counselor spiritual formation so that the content of the counseling is self-aware, committed to the love of God and neighbor, and interpreted through the lens of the Christian ground motive. Second, CEFT should incarnate the message of the King by embracing the client's temporal emotional experiences, while fostering a deeper examination of soul wounds revealed through explorations based on a Christian understanding of the inverse dialectic. Finally, CEFT should incarnate the methods of the King by promulgating a kerygmatic experiential counseling approach that activates, explores, expresses, and reflects intra-psychic, and interpersonal emotional conflicts. While much research remains to be done, future work should implement these three foundational requirements.

\section{Conflicts of Interest}

The author declares no conflict of interest.

\section{References and Notes}

1. Leslie S. Greenberg. Emotion-Focused Therapy. Washington, DC: American Psychological Association, 2011.

2. Robert Elliott, Jeanne C. Watson, Rhonda N. Goldman, and Leslie S. Greenberg. Learning Emotion-Focused Therapy: The Process-Experiential Approach to Change. Washington, D.C.: American Psychological Association, 2004.

3. Eric L. Johnson. Foundations for Soul Care: A Christian Psychology Proposal. Downers Grove, IL: IVP Academic, 2007. Kindle edition.

4. Paul David Tripp. Instruments in the Redeemer's Hands. Phillipsburg, NJ: P\&R Publishing, 2002.

5. Abraham Kuyper. Lectures on Calvinism. Grand Rapids, MI: Wm. B. Eerdmans, 1931. Kindle edition.

6. Henry Van Til. The Calvinistic Concept of Culture. Grand Rapids, MI: Baker Academic, 2001. Kindle file.

7. Stanton L. Jones, and Richard E. Butman. Modern Psychotherapies: A Comprehensive Christian Appraisal, 2nd ed. Downers Grove, IL: IVP Academic, 1991. Kindle edition.

8. Kelvin F. Mutter. "The Practice of Integration with Postmodern Therapies: Exploring the Use of Ingram's (1995) Model with Emotion Focused Therapy.” Journal of Psychology and Theology 40, no. 3 (2012): 179-87. 
9. Michael R. McFee, and Philip G. Monroe. “A Christian Psychology Translation of Emotion-Focused Therapy: Clinical Implications.” Journal of Psychology and Christianity 30, no. 4 (2011): 317-28.

10. Lydia Kim-Van Daalen, and Eric L. Johnson. Transformation in Christian Emotion-Focused Therapy. Downers Grove, IL: Intervarsity Press, in press.

11. Epistemology is the study of how we come to know things. An in-depth discussion of all of the nuances of this discipline lies outside the scope of this article; however, when I refer to epistemology, I am emphasizing the change process that yields new knowledge. In other words, I am highlighting the "way someone comes to know something”.

12. Lynne E. Angus, and Leslie S. Greenberg. Working With Narrative in Emotion-Focused Therapy: Changing Stories, Healing Lives. Washington, DC: American Psychological Association, 2011.

13. James W. Sire. Naming the Elephant: Worldview as a Concept. Downers Grove, IL: Intervarsity Press, 2004. Kindle edition.

14. Laura N. Rice, and Leslie S. Greenberg. History of Psychotherapy: A Century of Change. Edited by Donald K. Freedheim. Washington, D.C.: American Psychological Association, 1992.

15. Francis A. Schaeffer. A Christian Manifesto. Wheaton, IL: Crossway Books, 1981. Kindle edition.

16. For more information on Christian Ground Motive, see Herman Dooyeweerd. Roots of Western Culture: Pagan, Secular, and Christian Options. Toronto, ON: Wedge, 1979.

17. Sylvia Walsh. Living Christianly: Kierkegaard's Dialectic of Christian Existence. University Park, PA: The Pennsylvania University Press, 2005.

18. For an extended discussion on this subject, please see Marilyn G. Piety. Ways of Knowing: Kierkegaard's Pluralist Epistemology. Waco, TX: Baylor University Press, 2010.

19. Soren Kierkegaard. Point of View. Princeton, NJ: Princeton University Press, 2009, pp. 39-41.

20. John Owen. Indwelling Sin in Believers. Edinburgh, UK: Banner of Truth Trust, 1667.

21. Jonathan Edwards. Religious Affections: A Christian's Character before God. Vancouver, BC: Regent College Publishing, 1984.

22. John Calvin. Institutes of the Christian Religion. Grand Rapids, MI: Wm. B. Eerdmans, 1989.

23. Richard Sibbes. Light from Heaven. Lafayette, IN: Sovereign Grace, 2001.

24. Stephen Charnock. The Works of Stephen Charnock. London: James Nisbett and Company, 2010, vol. 5. Kindle edition.

25. Robert W. Kellemen. Soul Physicians. Winona Lake IN: BMH Books, 2007.

26. Eric L. Johnson. Resurrection Dialogues: The Therapeutic Resources of the Christian Faith. Downers Grove, IL: Intervarsity Press, forthcoming.

27. Francis A. Schaeffer. True Spirituality. Carol Stream, IL: Tyndale House, 2011. Kindle edition.

28. Cornelius Van Til. Psychology of Religion: In Defense of the Faith. Phillipsburg, NJ: P \& R Publishing, 1972, vol. 4.

29. While there is not an exact equivocation between the unconscious and the emotion scheme, they both represent psychic activity that occurs outside of the person's immediate awareness.

30. Soren Kierkegaard. A Kierkegaard Anthology. Princeton, NJ: Princeton University Press, 1946.

(C) 2014 by the author; licensee MDPI, Basel, Switzerland. This article is an open access article distributed under the terms and conditions of the Creative Commons Attribution license (http://creativecommons.org/licenses/by/3.0/). 